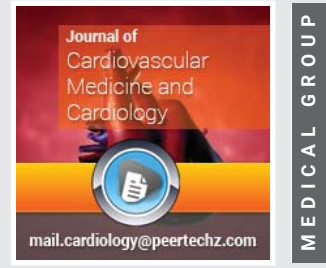

\title{
Should we prescribe abstinence or wine once a day with supper in diabetes and prediabetes?
}

\section{Kristian Rett*}

Endokrinologikum München, Promenadeplatz 12, D-80333, München, Deutschland, Germany

Received: 18 May, 2020

Accepted: 25 May, 2020

Published: 26 May, 2020

*Corresponding author: Kristian Rett, Endokrinologikum München, Promenadeplatz 12, D-80333, München, Deutschland, Germany, Tel: \#49 (162) 2874967; Fax: \#49 (89) 24296711;

E-mail: kristian.rett@amedes-group.com

https://www. peertechz.com

Check for updates

\begin{abstract}
The ultimate goal of diabetes management is to minimize complications and maintain quality of life in the context of comprehensive cardiovascular risk management and patient-centered care. This includes lifestyle management and diabetes self-management education and support. In contrast to current pharmacological guidelines, which are patient-centered and evidence based, lifestyle guidelines still carry potential for improvement. Despite current best evidence from prospective controlled trials showing, that moderate wine consumption is associated with survival benefit, reduced risk of cardiovascular endpoints in both subjects with and without diabetes as well as reduced diabetes incidence in the context of the mediterranean diet, translation into clinical practice is unsatisfactory. Patients with diabetes and prediabetes need balanced and accurate information so they can make informed decisions about the risk-benefit balance of the traditional mediterranean drinking pattern and translate it into their personal lifestyle and diabetes self-management - if applicable and suitable.
\end{abstract}

In this regard, balanced analysis of the available evidence as a counterbalance to notorious myths is necessary. This requires consideration of the broader context of european art of living, of direct and indirect effects of ethanol on glucose and lipid metabolism, distinction between harmful (binge drinking) and beneficial (regular with meals) drinking patterns, distinction between distilled (spirits) and fermented (wine and beer) beverages, appreciation of the phenomenon of dose-dependent effect reversal (hormesis or J-curve), which is common to all alcoholic beverages and finally respect of ethnical and regional as well as gender- and age-related differences.

\section{Abbreviations}

ADH: Alcohol Dehydrogenase; DSMS: Diabetes SelfManagement Education and Support; EtOH: Ethanol; MEDAS: Mediterranean Diet Adherence Screener

\section{Introduction}

There is a specter haunting Europe and North America: the specter of uncertainty and fear of alcoholic beverages. It has affected large parts of the general population, but in particular subjects with type 2 diabetes and prediabetes. This uncertainty calls for a balanced evaluation of the available evidence from prospective controlled trials enabling individuals with diabetes to make informed decisions.

Risky and harmful drinking patterns like the regular consumption of heavy amounts of wine, beer and spirits as well as excessive drinking on a single occasion (binge drinking) to the point of intoxication is undoubtedly harmful to human health. In contrast to that, conformity with a traditional mediterranean alcohol-drinking pattern (moderate intake throughout the week, low spirit consumption and avoidance of binge drinking, preference of wine, particularly red wine, wine consumption during meals) is associated with a variety of beneficial health aspects, particularly in diabetes and prediabetes.

Type 2 diabetes is a complex syndrome requiring coordinated interdisciplinary orchestration of drug and nondrug measures. Lifestyle in this context is much more than a distinct way of eating, but - close to the classical literal sense of diet ( $\delta i \alpha \imath \alpha ;[1])$ - includes comprehensive behavioural modification customized to the disease in several areas of life: food ( $\sigma \iota \tau\{\alpha$, sitía), drinks ( $\pi$ o $\langle$, potá), sport ( $\pi$ ovoı, ponoi), sleep ( $\eta \nmid \pi v o$, hýpnoi) and sexuality ( $\alpha \pi \eta \rho \circ \delta\{\sigma \iota \alpha$, aphrodísia). Despite a solid evidence base, the traditional mediterranean drinking pattern as core component of the intangible european 
cultural heritage of $\delta i \alpha \imath \alpha$, is not adequately represented in both diabetes guidelines and diabetes self-management education and support (DSMES) programs.

\section{Current diabetological paradigm shift}

The past decade has brought about an immense improvement in the evidence base for drug therapy of type 2 diabetes. This has led to a paradigm shift away from surrogate parameters and towards patient-centered care principles including focus on clinical endpoints that matter for the patient, and to preferencial use of drugs with proven cardiovascular benefit [2]. A similar paradigm shift is also taking place in medical nutrition, where we are witnessing relegation of both quantitative considerations and ineffective limitations of individual food components and macronutrients (calories, fats, carbohydrates, ethanol, etc.) whereas qualitative evaluation of health-promoting foods and nutritional styles with proven benefit are soaring [3-7].

Unfortunately, the part of the diabetes guidelines concerning lifestyle management is contradictory and not up to date with the current state of science $[2,5,6]$. For instance, it is generally accepted, that diabetes incidence and cardiovascular morbidity and mortality decline with increasing adherence to a mediterranean eating pattern [7-14]. Measurement of adherence as part of a detailed nutritional history may be implemented into DSMS programs using evaluated tools [1013; Table 1] in which moderate wine consumption consistently appears as one of 9 health-promoting components of the mediterranean diet [10-13].

Table 1: Modified 14-item Mediterranean Diet Adherence Screener (MEDAS) [11].

\section{MEDAS Question}

1. Do you use olive oil as the principal source of fat for cooking?

How much olive oil do you consume per day
salads, meals eaten away from home, etc.)?

3. How many servings of vegetables do you consume per day?

How many pieces of fruit (including fresh-squeezed juice) do you consume per day?

5. How many servings of red meat, hamburger, or sausages do you consume pe day?

6. How many servings of butter, margarine, or cream do you consume per day?

How many carbonated and/or sugar-sweetened beverages do you consume per day?

8. Do you drink wine? How much do you consume per week?

9. How many servings of pulses do you consume per week?

10. How many servings of fish/seafood do you consume per week?

How many times do you consume commercial (not homemade) pastry such as cookies or cake per week?

12. How many times do you consume nuts per week?

13. Do you prefer to eat chicken, turkey or rabbit instead of beef, pork,

13. hamburgers, or sausages? **

How many times per week do you consume boiled vegetables, pasta, rice, or other dishes with a sauce of tomato, garlic, onion, or leeks sautéed in olive oil?

\section{serving \\ size [g]}

use of olive oil for the preparation of at least 2 of the following groceries: salad, vegetable, meat/fish

$>48 \mathrm{~g}$ vegetable oil

$200 \geq 2$ portions of vegetables per day (including salad, olives, mushrooms)

$\geq 3$ portions of fruit (including mixed fruit, mixed stewed fruit and fruit juices)

$100-150<100 \mathrm{~g}$ meat (beef, veal, pork, lamb) and processed meat Products

$12<1$ portion butter, margarine and cream

$<1$ portion sugar-sweetened beverages per day (including lemonade and colas)

$\geq 7$ portions wine (red and white) per week *

$150 \geq 3$ portions pulses per week

$\geq 3$ portions fish, fish products and seafood per week

$<3$ portions cakes, chocolate, cookies, sweets with and without chocolate per week

$30 \geq 3$ portions nuts and seeds per week

$\mathrm{g}$ white meat (poultry, chicken, rabbit) $>\mathrm{g}$ red meat

(beef, veal, pork, lamb, processed meat products)

$>1-2$ times a week tomato sauce

\section{Color code for MEDAS recommendation: high consumption moderate consumption low consumption}

12 questions relate to frequency of consumption and 2 questions $(1,13)$ to specifics of the Mediterranean diet.

If the condition is not met, 0 points are recorded for the category. Adherence score ranges from 0 to 14 points. From 9 points upwards, high adherence is assumed

*We prefer a modification of the Trichopoulou-definition of moderate wine consumption [7,12] because it is gender-specific and defines a range (women 5 - $20 \mathrm{~g} / \mathrm{day}$, men $10-40 \mathrm{~g} /$ day) representing the hormetic associations of wine with human health. In addition to the original scorecard, adherence point 8 should only be given if the following caveats are warranted allowing for responsible consumption.

- youth protection (complete abstinence in adolescents),

- sobriety in the workplace and traffic,

- deliberate and consistent approach to abstinence:

o 1-2 abstinence days/week in general

o complete abstinence for pregnant/lactating women

o complete abstinence for subjects at increased risk of harm:

- family history of alcohol abuse and dependence

- mental health problems

- diseases/conditions that can deteriorate or be affected by alcohol

- use of certain over-the-counter or prescription medications, or recreational drugs

* 1 adherence point for vegetarians 
In contrast, the guidelines almost exclusively warn against the damage and addiction potential of excessive alcohol consumption and against the risk of hypoglycaemia [5,6]. Health benefits of moderate consumption and the different harm/benefit balances of different types of alcoholic beverages and drinking patterns $[8,15,16]$ are not adequately mentioned in the guidelines. Finally, the phenomenon of dose-dependent effect reversal (hormesis or J-curve), which is key to the question of the "right quantity" for alcoholic beverages in both types of diabetes $[15,17]$, is not addressed in the guidelines.

This leads to uncertainty and confusion among diabetes patients and health care professionals alike, especially since high-ranking journals with large global studies of lesser evidence but high ideological mission are outdoing each other, negating any risk-free alcohol consumption and calling for complete abstinence for all $[18,19]$. Here clarity of thought and wise medical decisions are required to empower our diabetes patients in the context of diabetes self-management education and support programs in order to protect them from media disinformation, prohibitionist contemporary spirit and notorious myths.

\section{Wine and metabolism: experimental data}

At the end of the $19^{\text {th }}$ century, the german nutrition and diabetes pioneer Carl von Noorden was able to almost halve glucosuria in his diabetes patients with what he called "oat days" and prandial administration of alcohol (wine during meals) [20]. Today we know that his observation was based on a complex interaction of ethanol effects and effects of phenolic and other naturally-occurring phytochemical compounds [21-25]. Even small amounts of ethanol act as comprehensive metabolic game changers: obligatory preferential ethanol degradation with simultaneously restrained lipid oxidation and insulin-independent antilipolysis as well as hepatic redoxand peripheral substrate-shift.

Thus, hepatic glycogenolysis is stimulated, which can lead to increased plasma glucose levels in the short term when the glycogen stores are full, but empties the glycogen store in the longer term. Together with the inhibition of hepatic gluconeogenesis, post-absorptive glucose production thus decreases. This constellation is undesirable and potentially dangerous when glycogen stores are empty, which is why diabetes patients should consume wine only with food [15, 21]. A further ethanol consequence is the increased synthesis and esterification of fatty acids with simultaneously reduced mitochondrial $\beta$-oxidation, which leads to a slightly increased hepatic lipid synthesis in the balance [22].

Ethanol prompts the liver to release an additional oxidizable substrate (acetate) which by displacing free fatty acids as the preferred substrate of peripheral tissues reduces lipolysis [22].

Experimental data show increased skeletal muscle glucose uptake in the presence of lifelike ethanol concentrations. Thus, yet in insulin-free muscle fibre preparations, ethanol elicits an insulin-like effect on glucose transport [23].
In addition, experimental data show, that phenolic compounds jointly improve glucose metabolism, endotheliumdependent vasodilation, blood pressure, platelet function, and inflammation [24]. Accordingly, polyphenols, flavonoids and stilbenes are associated with reduced diabetes prevalence in prospective studies [25]. Drinking wine with food has been shown to increase the capacity to overcome post-prandial oxidative stress [15].

\section{Prospective studies}

The ADVANCE (Action in Diabetes and Vascular Disease: Preterax and Diamicron Modified Release Controlled Evaluation) study is one of the three large diabetes studies that have prompted the above-mentioned paradigm shift $[26,27]$. In factorial design, 11.140 participants with type 2 diabetes (37\% Asians, 4\% North Americans, 15\% current smokers; age $66 \mathrm{y}$, diabetes duration $8 \mathrm{y}$, baseline HbA1c $7.5 \%$, baseline blood pressure $145 / 81 \mathrm{mmHg}$ ( $75 \%$ on antihypertensive treatment), baseline BMI $28.3 \mathrm{~kg} / \mathrm{m}^{2}$ ), high cardiovascular risk or previous cardiovascular disease (32\%), active blood pressure intervention (single-pill fixed-dose combination of perindopril and indapamide) and sulfonylurea-based forced HbA1c-lowering the range $<6-6.5 \%$ were compared with standard treatment over a period of 4.8 years.. According to common perception, active blood pressure intervention significantly reduced the primary composite end point (major macrovascular or microvascular events) as well as secondary endpoints like risk of death from any cause and from cardiovascular causes [26]. However with sulfonylurea-based forced HbA1c-lowering only the surrogate parameter albuminuria progression decreased, whereas patient relevant micro- and macrovascular endpoints remained unaffected [27].

Self-reported data on drinking behaviour at the time of randomization were available for $30 \%$ of the ADVANCE study participants. These data were correlated with clinical endpoints in a post-hoc subgroup analysis [28]. Surprisingly, cardiovascular events, microvascular complications and allcause mortality were lower by 17,15 and $13 \%$ with moderate alcohol consumption compared with abstainers. This finding is even more pronounced with moderate wine consumption with 22,15 and $23 \%$ relative risk reduction (Table 2 ).

Cardiovascular benefit disappears with larger drinking quantities: heavy drinkers had a dose-dependent higher risk of cardiovascular events and death compared with abstainers. Thus, macrovascular and microvascular risk as a function of drinking behavior follows a typical hormetic (dose-dependent effect reversal) J-shaped curve. Even when considering absolute risk reduction as a prerequisite to calculate effect sizes and numbers needed to treat, the behavioral trait moderate wine consumption compared well with or even trumps the impact of reducing blood pressure and HbA1c. However, caution is warranted in order to avoid premature conclusions: this is a post-hoc evaluation, effect sizes from the prospective pharmacological intervention and the behavioral trait are in fact not comparable. In addition, potential confounders (cultural and social inhomogeneity with regard to drinking behavior mediterranean-like lifestyle per se) and the presumably high 
Table 2: Comparative impact of the investigated intervention / behavioral trait in ADVANCE. Relative risk reduction (RRR; \%) und number needed to treat (NNT).

\begin{tabular}{|c|c|c|c|}
\hline & \multicolumn{3}{|c|}{$\begin{array}{c}\text { RRR; \% / NNT } \\
\text { [level of significance] }\end{array}$} \\
\hline & $\begin{array}{c}\text { Forced HbA1c-reduction [26] } \\
6,4 \% \text { vs. } 7,4 \% \\
\Delta 1,0 \%\end{array}$ & $\begin{array}{c}\text { Active blood pressure treatment [27] } \\
135 / 73 \text { vs. } 140 / 75 \mathrm{mmHg} \\
\Delta 5 / 2 \mathrm{mmHg}\end{array}$ & $\begin{array}{l}\text { Wine consumption [28] } \\
\text { moderate* vs. abstinent } \\
\Delta \leq 20+/ \leq 30{ }^{-} \text {gEtOH }\end{array}$ \\
\hline Cardiovascular endpoints & $\begin{array}{c}6 / 166 \\
0,32\end{array}$ & $\begin{array}{c}8 / 143 \\
0,16\end{array}$ & $\begin{array}{c}22 / 59 \\
0,001\end{array}$ \\
\hline Microvascular endpoints & $14 \underset{0,01}{/} 67$ & $\begin{array}{l}9 / 143 \\
0,16\end{array}$ & $\begin{array}{c}15 / 33 \\
0,12\end{array}$ \\
\hline Total mortality & $\begin{array}{c}7 / 142 \\
0,28\end{array}$ & $\begin{array}{c}14 / 83 \\
0,025\end{array}$ & $\begin{array}{c}23 / 83 \\
0,02\end{array}$ \\
\hline
\end{tabular}

*<14 (women) or $<21$ (men) standard drinks (à $125 \mathrm{~mL}$ ) within a week, equivalent to $<20 \mathrm{~g} / \mathrm{d}$ or $<30 \mathrm{~g} / \mathrm{d}$ Ethanol (EtOH)

Color code : $\quad$ statistically significant and clinically relevant

number of participants with genetic alcohol intolerance [29], leaves the ADVANCE data hypothesis-generating at best.

The CASCADE study [CArdiovaSCulAr Diabetes \& Ethanol; 30,31] examined the effect of moderate wine consumption in a cohort of 224 non-smoking, well-controlled type 2 diabetic participants without previous cardiovascular damage (age 60 y, baseline HbA1c $6.9 \%$, baseline blood pressure $131 / 78 \mathrm{mmHg}$ ( $45 \%$ on antihypertensive treatment), baseline BMI $30.0 \mathrm{~kg} /$ $\mathrm{m}^{2}$ ). They consumed either $150 \mathrm{ml}$ of red or white wine or mineral water for dinner over a period of two years within an isocaloric mediterranean diet accompanied by nutritional monitoring. Although only surrogate parameters (lipid profile, glycemic parameters, blood pressure) were defined as primary endpoints, this study still represents a milestone in nutritional research due to randomization, homogeneous patient cohort that had not regularly consumed alcohol up to the start of the study and complete assessment of the variants of alcohol dehydrogenase (ADH). The effects on the lipid profile essentially reproduce known effects of moderate wine consumption - with slight advantages in favour of red wine. Stratified by genotype variants of $\mathrm{ADH}$, significant differences in blood pressure and glycaemic parameters (HbA1c, fasting plasma glucose, insulin) were found, which suggest that these are ethanol-mediated effects. On the other hand, neither weight gain nor a change in fat distribution was observed [32], although alcohol is traditionally considered high in calories on its own.

PREDIMED (Prevención con Dieta Mediterránea [11]) is a multicentre parallel group study for primary prevention in which 7.447 subjects (97\% white Europeans, age 67 y) with either type 2 diabetes (approx. 50\%), or high cardiovascular risk ( $14 \%$ current smokers; $83 \%$ hypertension, $72 \%$ dyslipidemia, baseline BMI $30.2 \mathrm{~kg} / \mathrm{m}^{2}$ ) were randomised into 3 groups: low fat (control group) or two groups with a Mediterranean diet and either olive oil or nut supplement ( $50 \mathrm{ml}$ per day of a highquality (i.e. polyphenol-rich) olive oil or $30 \mathrm{~g}$ of a nut mixture (15 $\mathrm{g}$ walnuts and $7.5 \mathrm{~g}$ hazelnuts or almonds each).

Nutritional monitoring neither included calorie reduction nor recommendations concerning physical activity, but essentially the 14 criteria from Table 1. Criterion No. 8 ["at least 7 glasses of wine per week at mealtime" (only for participants who already consumed wine before participating in the study)] was met by a quarter of the participants in the control group and a third in the Mediterranean group. Both proportions appear unexpectedly low for Spain, possibly reflecting prevalent uncertainty of both diabetes- and highrisk patients as to whether the cultural heritage of moderate wine use is detrimental or beneficial.

In PREDIMED the primary composite endpoint (cardiovascular death, fatal/non-fatal myocardial infarction/ stroke) was reduced by about $30 \%$ in both mediterranean diet groups during the observation period of 4.8 years.

The prospective MOLI-SANI cohort study [12] in 1.995 subjects with type 2 diabetes (age $63 \mathrm{y}, 13 \%$ cardiovascular disease, $19 \%$ current smokers, $83 \%$ hypertension, $41 \%$ hypercholesterolemia) showed survival benefit with increasing adherence to the Mediterranean diet within a 4-year observation period. MOLI-SANI also proves that moderate wine consumption in the context of a mediterranean diet is the single trait with the highest achievable benefit on survival [12]. Accordingly, moderate consumption of alcohol in the form of wine with meals is "the component of the Mediterranean diet with the greatest beneficial influence on cardiovascular health of subjects with type 2 diabetes".

We should by no means indiscriminately encourage our diabetes patients to drink alcohol. But lifestyle advice in DSMES programs requires evidence-based and balanced information about the fact, that moderate wine consumption is one of the 9 recommended components of the mediterranean diet, that might be particularly beneficial for them (Tables 1,3 ).

Table 3: Traditional mediterranean drinking pattern „prescription“ customized for subjects with type 2 diabetes or prediabetes.

\begin{tabular}{l|c|c|}
\hline Prescription & Latin & English \\
\hline Bib. & bibe & drink \\
\hline Vinum & vinum & wine \\
\hline $\begin{array}{l}\text { Cyath. vinos. }(125 \mathrm{~mL}) \\
\text { C. cib. }\end{array}$ & cyathus vinosus & one wine-glassful \\
\hline Q.p.m. & quaque cibus & with food \\
\hline S.a. & secundum artem & according to best practice \\
\hline NMT $250 \mathrm{~mL}(+) / 500 ~ \mathrm{ml}\left({ }^{\Uparrow}\right)$ & & not more than ... \\
\hline Q.wk. abstinentia & quaque septimana & once a week sobriety \\
\hline
\end{tabular}




\section{References}

1. Hippocrates. Of the epidemics. In: Hippocrates Collected Works I. Jones WHS (1868) Cambridge. Harvard University Press.

2. Davies MJ, D'Alessio DA, Fradkin J, Kernan WN, Mathieu C, et al. (2018) Management of hyperglycaemia in type 2 diabetes. A consensus report by the American Diabetes Association (ADA) and the European Association for the Study of Diabetes (EASD). Diabetologia 61: 2461-2498.

3. Shai I et al (2008) Dietary Intervention Randomized Controlled Trial (DIRECT) Group. Weight loss with a low-carbohydrate, Mediterranean, or low-fat diet. N Engl J Med 359: 229-241.

4. Mozaffarian D, Appel LJ, Van Horn L (2011) Components of a cardioprotective diet. New insights. Circulation 123: 2870-2891. Link: https://bit.ly/2Xug9I0

5. American Diabetes Association (2017) Lifestyle management. Sec. 4. In Standards of Medical Care in Diabetes. Diabetes Care 40: S33-S43.

6. Evert AB, Dennison M, Gardner CD, Garvey WT, Lau KH, et al. (2019) Nutrition Therapy for Adults With Diabetes or Prediabetes: A Consensus Report. Diabetes Care 42: 731-754. Link: https://bit.ly/2TyCyfJ

7. Trichopoulou A, Costacou T, Bamia C, Trichopoulos D (2003) Adherence to a Mediterranean Diet and Survival in a Greek Population. N Engl J Med 348: 2599-2608. Link: https://bit.ly/2Zyr93u

8. Neuenschwander M, Ballon A, Weber KS, Norat T, Aune D, et al. (2020) Role of diet in type 2 diabetes incidence: umbrella review of metaanalyses of prospective observational studies. BMJ 366: 12368. Link: https://bit.ly/3gl2Zzp

9. Fung TT, Rexrode KM, Mantzoros CS, Mansoon JE, Willett WC, et al. (2009) Mediterranean diet and incidence of and mortality from coronary heart disease and stroke in women. Circulation 119: 1093-1100. Link: https://bit.ly/2Zzjulc

10. Buckland G, Agudo A, Travier N, Huerta JM, Cirera L, et al. (2011) Adherence to the Mediterranean diet reduces mortality in the Spanish cohort of the European Prospective Investigation into Cancer and Nutrition (EPIC-Spain). $\mathrm{Br}$ J Nutr 106: 1581-1591. Link: https://bit.ly/36Ap5tq

11. Estruch R, Ros E, Salas-Salvadó J, Covas MI, Corella D, et al. (2018) Primary prevention of cardiovascular disease with a Mediterranean diet supplemented with extra-virgin olive oil or nuts. N Engl J Med 378: 1279-1290. Link: https://bit.ly/36uu3rw

12. Bonaccio M, Di Castelnuovo A, Costanzo S, Persichillo M, De Curtis A, et al (2016) on behalf of the MOLI-SANI Study Investigators. Adherence to the traditional Mediterranean diet and mortality in subjects with diabetes. Eur $J$ Prev Cardiol 23: 400-407. Link: https://bit.ly/3dd5AcA

13. O'Connor LE, Hu EA, Steffen LM, Selvin E, Rebholz CM, et al. (2020) Adherence to a Mediterranean-style eating pattern and risk of diabetes in a U.S prospective cohort study. Nutrition and Diabetes 10: 8. Link: https://go.nature. com/2XwgcwC

14. Esposito K, Maiorino MI, Ceriello A, Giugliano D (2010) Prevention and contro of type 2 diabetes by Mediterranean diet: a systematic review. Diabetes Res Clin Pract 89: 97-102. Link: https://bit.ly/3ejEsJ4

15. Boban M, Stockley C, Teissedre PL, Restani P, Fradera U, et al. (2016) Drinking pattern of wine and effects on human health: why should we drink moderately and with meals? Food Funct 7: 2937-2942. Link: https://bit.ly/2X1910u

16. Schutte R, Papageorgiou M, Najlah M, Huisman HW, Ricci C, et al. (2020) Drink types unmask the healthy risks associated with alcohol intake. Prospective evidence from the general population. Clinical Nutrition Link: https://bit.ly/3d38y3r
17. Beulens JWJ, Kruidhof JS, Grobbee DE, Chaturvedi N, Fuller FH, et al (2008) Alcohol consumption and risk of microvascular complications in type 1 diabetes patients: the EU-RODIAB Prospective Complications Study. Diabetologia 51: 1631-1638. Link: https://bit.ly/2TzqYB8

18. Wood AM, Kaptoge S, Butterworth AS, Willeit P, Warnakula S, et al. (2018) Risk Thresholds for Alcohol Consumption: Combined Analysis of IndividualParticipant Data for 599912 Current Drinkers in 83 Prospective Studies. Lancet 391: 1513-1523. Link: https://bit.ly/2WYvlb2

19. Gakidou E, Griswold MG, Fullman N, Hawley CN, Arian N, et al. (2018) Alcohol use and burden for 195 countries and territories, 1990-2016: a systematic analysis for the Global Burden of Disease Study Lancet 392: 1015-1035. Link: https://bit.ly/2AWZajH

20. Noorden C, Isaac S (1901) Die Zuckerkrankheit und ihre Behandlung. 3. Auflage, 4. Kapitel S. 83; August Hirschwald, Berlin. Link: https://bit.ly/2A35oyf

21. Turner BC, Jenkins E, Kerr D, Sherwin RS, Cavan DA (2001) The effect of evening alcohol consumption on next-morning glucose control in type 1 diabetes. Diabetes Care 24: 1888-1893. Link: https://bit.ly/3gmJdnl

22. Siler SQ, Neese RA, Hellerstein MK (1999) De novo lipogenesis, lipid kinetics, and whole-body lipid balances in humans after acute alcohol consumption. Am J Clin Nutr 70: 928-936. Link: https://bit.ly/2M2uiAt

23. Yu B, Schroeder A, Nagy LE (2000) Ethanol stimulates glucose uptake and translocation of GLUT-4 in H9c2 myotubes via a Ca2+-dependent mechanism. Am J Physiol Endocrinol Metab 279: E1358-E1365. Link: https://bit.ly/3c7eVBK

24. Heiss C, Keen CL, Kelm M (2010) Flavanols and cardiovascular disease prevention. Eur Heart J actions 31: 2583-2592. Link: https://bit.ly/3gmsrEQ

25. Tresserra-Rimbau A, Guasch-Ferrè M, Salas-Salvadó J (2016) Intake of Total Polyphenols and Some Classes of Polyphenols Is Inversely Associated with Diabetes in Elderly People at High Cardiovascular Disease Risk. J Nutr 146 767-777. Link: https://bit.ly/3eflldL

26. Patel A, MacMahon S, Chalmers J, Neal B, Woodward M, et al. (2007) Effects of a fixed combination of perindopril and indapamide on macrovascular and microvascular outcomes in patients with type 2 diabetes mellitus (the ADVANCE trial): a randomised controlled trial. Lancet 370: 829-840. Link: https://bit.ly/2WXMGB2

27. The ADVANCE Collaborative Group (2008) Intensive blood glucose control and vascular outcomes in patients with type 2 diabetes. N Engl J Med 358 2560-2572. Link: https://bit.ly/3c0b74Y

28. Blomster Jl, Zoungas S, Chalmers J, Li Q, Chow CK, et al. (2014) The relationship between alcohol consumption and vascular complications and mortality in individuals with type 2 diabetes. Diabetes Care 37: 1353-1359. Link: https://bit.ly/2ZAD6G4

29. Li H, Borinskaya S, Yoshimura K, Kal'ina N, Marusin A, et al. (2009) Refined geographic distribution of the oriental ALDH2*504lys variant. Ann Hum Genet 73: 335-334. Link: https://bit.ly/36EqlMd

30. Gepner Y, Golan R, Harman-Boehm I, Henkin Y, Schwarzfuchs D, et al. (2015) Effects of Initiating Moderate Alcohol Intake on Cardiometabolic Risk in Adults With Type 2 Diabetes. A 2-Year Randomized, Controlled Trial. Ann Intern Med 163: 569-579. Link: https://bit.ly/3elte7b

31. Gepner Y, Henkin Y, Schwarzfuchs D, Golan R, Durst R, et al. (2016) Differentia Effect of Initiating Moderate Red Wine Consumption on 24-h Blood Pressure by Alcohol Dehydrogenase Genotypes: Randomized Trial in Type 2 Diabetes. Am J Hypertens 29: 476-483. Link: https://bit.ly/2zsyfMm

32. Golan R, Shelef I, Shemesh E, Henkin Y, Schwarzfuchs D, et al. (2017) Effects of initiating moderate wine intake on abdominal adipose tissue in adults with type 2 diabetes: a 2-year randomized controlled trial. Public Health Nutr 20 549-555. Link: https://bit.ly/2XyiLyy

Copyright: (c) 2020 Rett K. This is an open-access article distributed under the terms of the Creative Commons Attribution License, which permits unrestricted use distribution, and reproduction in any medium, provided the original author and source are credited.

Citation: Rett K (2020) Should we prescribe abstinence or wine once a day with supper in diabetes and prediabetes? J Cardiovasc Med Cardiol 7(2): 152-156. DOI: https://dx.doi.org/10.17352/2455-2976.000131 